\section{Mental Health throughout the World}

DuRnNG June 1961 an International Study Group met at the Roffey Park Institute, Horsham, to discuss international aspects of mental health. Its primary function was to make a broad survey of the progress being made in the many aspects of mental health field throughout the world. An attempt was made to cover the spectrum of interests from research and care of the mentally sick at one end, to international relationships at the other (Mental Health in International Perspective. Pp. 84. London and New York: World Federation for Mental Health, 1961).

\section{Causes of Deafness in Schoolchildren}

A TOTAL of 270 children born in Northumberland and Durham during the years 1945-54 are receiving education in schools for the deaf. This represents an incidence of severe deafness of 0.7 per 1,000 , the same as the national incidence. Dr. M. E. Barton, Dr. S. D. Court and Dr. W. Walker of the Department of Child Health, Durham University Medical School, King's College, Newcastle upon Tyne, have studied the early medical history and family background of these children (Brit. Med. J., 5275; February 10, 1962). Twenty-five per cent were classified as having hereditary deafness, in 25 per cent deafness followed meningitis or some other infection, but in 50 per cent the cause of deafness was unknown. Of the unexplained cases there was a history of maternal rubella during the first three months of pregnancy in two instances, while two more of the children had suffered from severe hæmolytic disease of the newly born. Of the remainder, 21 per cent were 'premature' infants, 7.6 per cent having a birth weight of $4 \mathrm{lb}$. or less. Only 18 per cent of the premature infants gave a history of severe jaundice, and it would appear that prematurity even in the absence of jaundice may be an important cause of deafness.

\section{Influence of Diet on the Incidence of Athero- sclerosis}

Dr. M. Toor, Prof. A. Katzir and Dr. I. Agmon have carried out an investigation of the socio-economic conditions, diet and serum cholesterol-levels of 2,680 immigrants to Israel from Eastern and Western countries belonging to different social groups (Dapim Refuiim, 11, No. 1; January 1962). The lowest serum cholesterol values were found among 'recent' Yemenites, the least fortunate economically and with an imbalanced intake and the lowest fat content. Higher cholesterol values were found among the early Yemenites and European manual workers whose diet was richer in calories and a percentage of calories derived from fats. In middle class Europeans the serum cholesterol-levels were still higher. A positive correlation was found between these serum cholesterol-levels and morbidity and mortality from atherosclerosis for the different groups investigated. The results support the assumption that atherosclerosis is a disease of lipid metabolism in which diet is a dominant factor.

\section{Schistosomiasis}

The latest issue of Phoenix is concerned with schistosomiasis or bilharziasis $(1$, No. 3; December 1961. Bilharziasis/Schistosomiasis. Pp. 16. Ann Arbor, Michigan: Michigan Memorial-Phoenix Project, The University, 1961). Estimates of the number of people afflicted with schistosomiasis range from 114 million to 200 million. These infested people live principally in agricultural communities in Asia,
Africa and South America. In many areas, particularly Asia, schistosomiasis is also a disease of animals, thus adding detrimental economic effects to its human toll. Because of the growing number of countries in which the disease is known to exist, and because of the extension of the snail habitats in these countries and the growing number of infested people, schistosomiasis has become one of the worst diseases in the world. The interest of the Phoenix Project in schistosomiasis stems from a research programme supported by the Project and conducted in the Phoenix Memorial Laboratory, University of Michigan. The investigators are using radiation from a cobalt-60 source in an attempt to create a vaccine that will provide immunity to the disease.

\section{Paralytic Rabies in Greenland}

For at least a hundred years epizootics of a disease resembling rabies have raged among the sledge dogs of Northern Greenland. In 1859 Dr. N. Rudolph, medical supervisor of the Upernavik district, described the clinical picture in dogs of extreme exhaustion, hydrophobia, abundant secretion from the mouth, and weakness of the hind legs. In the initial stage the disease was clearly epidemic. Between 1864 and 1865 a similar outbreak occurred in the northern districts. In $1908 \mathrm{Mr}$. S. R. Hjortlund described a highly contagious and deadly epizootic in dogs: in most cases the disease ran a quiet paralytic course, but a few dogs were aggressive. The cause of the disease was never established, but it was noted that often the disease broke out a few days or weeks after fights between dogs and 'mad' polar foxes. Because rabies is widespread among arctic foxes and other animals in Canada, it was assumed that Canadian foxes traversing the icebound Davis Strait had transmitted the disease to Greenland foxes, which in turn had transferred it to the dogs. This, however, was never proved, and only recently have the combined efforts of American and Danish laboratories shown that the canine disease is true rabies. In recent years canine epizootics have been numerous. Four outbreaks between 1957 and 1960 played havoc among the dogs in northern Greenland, and nearly caused famine among the Eskimos, to whom the dogs are indispensable. All the affected dogs died-a fact suggestive of rabies-and extensive vaccination of the dogs against rabies rapidly stopped the spread. Despite the recurrent canine epizootics, not a single human case of rabies has previously been reported from Greenland, where adults, and especially children, are often attacked and severely bitten by aggressive dogs. Prof. H. C. A. Lassen, of the University of Copenhagen, now describes an unequi. vocal case of human rabies from Greenland (The Lancet, 7223; February 3, 1962). The disease ran an exclusively paralytic course.

\section{New Zealand Barrier Island Study}

The Little Barrier Island (Hauturu to the Maoris) is a nature reserve lying some 50 miles north-east of Auckland. Bulletin 137 of the New Zealand Department of Scientific and Industrial Research provides an admirable and detailed account of the Island accompanied by clear, well-drawn and relevant maps (Little Barrier Island (Hauturu). Compiled by W. M. Hamilton. Second edition. Pp. $198+4$ maps. Wellington: Government Printer, 1961. 30s.). The story of the nature reserve is quite interesting. By 1896, the year the reserve was established, about one-third of the natural forest had been modified by 